\section{DEVELOPMENT OF FORCED COOLING USING MIST OF STRONG ALKALINE WATER FOR RESTRAINING THERMAL DEFORMATION ON A MACHINE TOOL}

I. TANABE

NTU, Deptartment of Mechanical Engineering Nagaoka, Niigata, Japan

e-mail: tanabe@mech.nagaokaut.ac.jp

In this research, forced cooling using mist of strong alkaline water for restraining thermal deformation on a machine tool was developed and evaluated. There are the corrosion resistance of several materials without aluminum, copper and their alloys in alkaline water. Thermal deformations of the bench lathe were effectively restrained by mist of strong alkaline water. When mist of alkaline water was used in the cutting territory, tool temperature during cutting with steel could reduce to $60 \%$, surface roughness on the work piece at limit of tool

life could improve $50 \%$ and the tool life becomed 2.4 times.

KEYWORDS

machine tool, thermal deformation, forced cooling, water evaporation, strong alkaline water, mist

\section{INTRODUCTION}

In the 21 st century, as it is important to produce the products with high accuracy, high quality and eco-friendly, the most of manufacturers need several daring plans, unique ideas and new technologies [Tanabe 1999, Tanabe 2003, Kaneko 2004]. For example, in machine tool technology, restraint of thermal deformation on a machine tool was required for high accuracy and quality, and several countermeasures using costly equipment and large quantity of electrical energy were used for the restraint [Tanabe 2011, Tanabe 2000, Tanabe 2001], however those countermeasures are not enough.

Therefore, In this research, forced cooling using mist of strong alkaline water for restraining thermal deformation on a machine tool was developed and evaluated. Most materials were not corroded by strong alkaline water and mist of the strong alkaline water has very large cooing effect because of its water evaporation. Corrosion test was firstly performed for several materials during 2 months. Then mist of strong alkaline water was supplied around the structure of the machine tool and the territory of machining for restraining thermal deformation and removing heat generation of machining on the machine tool, respectively. Bench lathe and CNC milling machine were used for the experiments. Thermal deformation of the bench lathe was measured for evaluation of forced cooling with mist of the strong alkaline water. The effects of mist of strong alkaline water were lastly evaluated regarding tool temperature during cutting, surface roughness on the work piece and the tool life by CNC milling machine.

\section{CORROSION RESISTANCE FOR STRONG ALKALINE WATER}

In factories, the use of water in machine tools is small [Tanabe and Truong 2001]. Because water will create corrosion in the steel parts or some machine elements. However, when the $\mathrm{pH}$ of the strong alkaline water exceeds $\mathrm{pH} 12.5$, the steel parts will not be corrode by it. Also lately in order to eliminate bacteria and prevent the growth of microorganisms, it has been used as a cleaning agent in wide areas. Here, properties of alkaline water in machine toolsis revealed in the experiments. As shown in the specifications, with a small generator is possible to produce strong alkaline water of $\mathrm{pH} 12.5$ very easily. According to the field of corrosion engineering, in an equilibrium state when the logarithm value of metal ion concentration $(\mathrm{mol} / \mathrm{l})$ is lower than -6 [Simohira, 1995], the metal will not be corroded. Therefore, related to the corrosion properties of strong alkaline water in the case of steel, it will be necessary alkaline water with $\mathrm{pH} 10$ or more over for not being corroded. As well, for making a nickelbased alloy, the nickel needs a pH $8.5 \sim \mathrm{pH} 13.0$ range for being in a chemically passive state. Also, for titanium-based alloy, the titanium needs a below pH 13.0. From here, for a tool of titanium-based alloy or nickel-based alloy being used while is dip in strong alkaline water and cooled by it reducing the thermal effects in the tool, the use of a strong alkaline water with a value of $\mathrm{pH} 10.0 \sim 13.0$ is appropriate. Also it can be used for coolingpurposes. It was confirmed by experiments the properties of these materials in alkaline water against corrosion. The condition of corrosion test was shown in the Table 2. During a period of two months these materials were left in alkaline water in a room with constant temperature of $20 \pm 1{ }^{\circ} \mathrm{C}$ and a humidity of $60 \%$. The alkaline water was replaced once a week maintaining the $\mathrm{pH}$ at 12.5 .

\begin{tabular}{|c|c|c|c|}
\hline \multicolumn{2}{|c|}{ Work piece materials } & \multicolumn{2}{|c|}{ Tool materials } \\
\hline \multirow{2}{*}{ Ti (pure) } & \multirow{2}{*}{ O } & High speed tool & 0 \\
\hline & & Carbide (S30T, T725X) & 0 \\
\hline \multirow{2}{*}{ Ti6Al4V } & \multirow{2}{*}{0} & Cermet (NS530) & 0 \\
\hline & & Ceramics (LX11) & 0 \\
\hline \multirow{2}{*}{ Inconel 718} & \multirow{2}{*}{0} & CBN (KBN525) & 0 \\
\hline & & Diamond (DA2200) & 0 \\
\hline Steel (S45C) & 0 & \multicolumn{2}{|c|}{ Coating materials of tool } \\
\hline Aluminum & $x$ & $\mathrm{TiN}$ & 0 \\
\hline \multirow{2}{*}{ Copper } & \multirow{2}{*}{ Color change } & $\mathrm{TiC}$ & 0 \\
\hline & & DLC & 0 \\
\hline \multirow{2}{*}{ Brass } & \multirow{2}{*}{ Color change } & TiAIN & $x$ \\
\hline & & $\mathrm{TiAlCr}$ & $x$ \\
\hline
\end{tabular}

Table 1. Results of the materials tested in strong alkaline water with $\mathrm{pH} 12.5$ (for two month)

In the Tab. 1 is shown the results of the materials testes in strong alkaline water with $\mathrm{pH} 12.5$ during 2 months (Room temp: $20^{\circ} \mathrm{C}$ Humidity: $60 \%$ ). In addition to pure titanium, titanium alloys, and nickel-based alloys, was also tested in workpiece as steel (S45C), aluminum, copper, brass; also in tools like high speed steel tools, carbide, cermet, ceramics, $\mathrm{CBN}$ and diamond; finally in coating materials of tool like TiN, TiC, DLC, TiAIN and TiAlCr. Metals such as aluminum, aluminum alloys, copper, non-copper alloy after the two months in strong alkaline water presented corrosion. As is shown in the Tab. 3, the color ofthe metal like copper and brass changed in a darker color. In the other hand, steel, titaniumalloys, nickel alloys did not presented corrosion being immersed in strong alkaline water, so is possible to think in using this method for cutting.

\section{COOLING PROPERTY FOR MIST WITH STRONG ALKALINE WATER}

New nozzle was manufactured for making mist of strong alkaline water such as Fig. 1. The nozzle consists of an air tube $(1 \times 7 \mathrm{~mm})$ and a tube $(1 \times 7 \mathrm{~mm})$ of strong alkaline water.

Then cooling property for mist with strong alkaline water was measured in experiment. Experimental set-up is shown in Fig. 2. A sensor for measuring heat transfer coefficient and a manufactured nozzle were set in the center of the vessel $(556 \times 386 \times 310 \mathrm{~mm})$. Sensor for measuring heat transfer coefficient is self consists of a ceramic heater $(5 \times 5 \times 1.75 \mathrm{~mm})$, two steel plates $(5 \times 5 \times 0.06 \mathrm{~mm})$ 


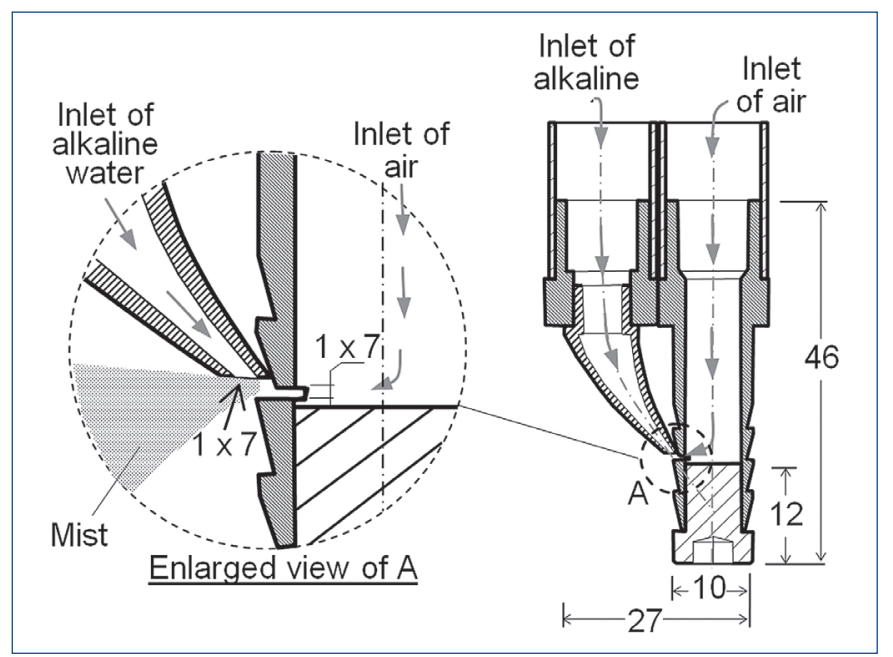

Figure 1. Schematic view of nozzle for mist of strong alkaline water

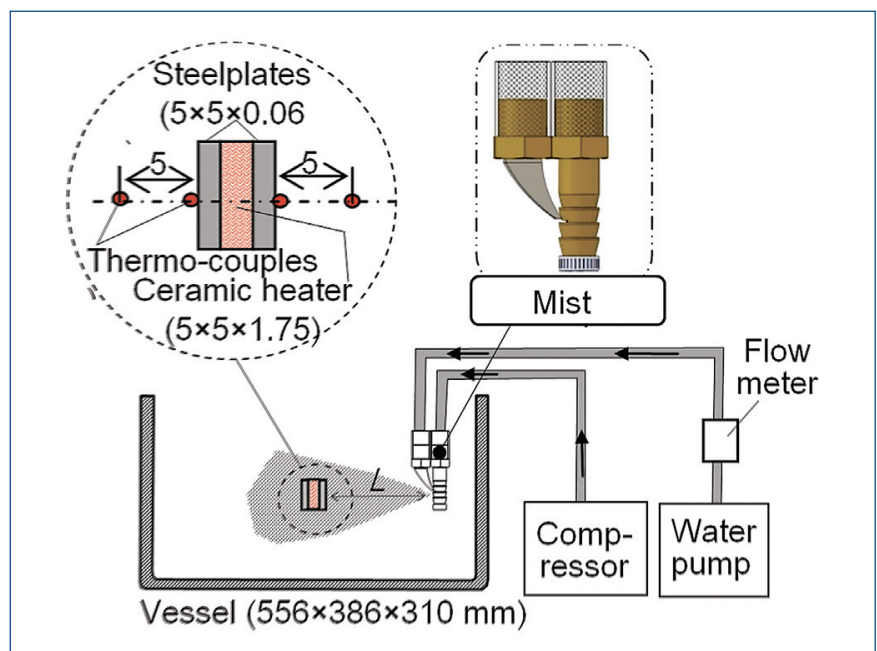

Figure 2. Experimental set-up for measuring heat transfer coefficient regarding mist of strong alkaline water

and 4 thermo-couples. The ceramic heater got caught between both two steel plates and is inputted electric power $E(7.8 \mathrm{~W})$. At this time, temperature on the steel plate becomes about $100^{\circ} \mathrm{C}$ in the air. Two thermo-couples are measured temperatures $T_{w 1}$ and $T_{w 2}$ on the center of the each steel plate respectively. Other two thermo-couples are measured temperatures $T_{M 1}$ and $T_{M 2}$ of mist with strong alkaline water on the $5 \mathrm{~mm}$ distance from the each steel plate respectively. Heat transfer coefficient $\alpha$ is calculated by equation (1).

$$
\alpha=\left(\frac{E / 2 E / 2}{A \cdot\left(T_{\mathrm{w} 1}-T_{\mathrm{M} 1}\right) A \cdot\left(T_{\mathrm{w} 2}-T_{\mathrm{M} 2}\right)}\right.
$$

where $\mathrm{A}(5 \times 5 \mathrm{~mm})$ is area of steel plate. Average of heat transfer coefficient on twice steel plates is calculated. Because influence of radiation is also included in this heat transfer coefficient, this value is appearance heat transfer coefficient. However we thought that this is used for evaluation of cooling property because of similar condition to several manufacturing or machining fields.

Relationship betweenthe heattransfer coefficient and the mixture ratio of air and strong alkaline water was shown in Fig. 3. Length $L$ from output noozle to measuring point was used $225 \mathrm{~mm}$. Paramete is total flow rate of strong alkaline water. There are two peaks in this fugure; one is mist condition (Small strong alkaline water) which has very large forced cooling effect because of heat of vaporization. More one is fluid condition (Small air) which has very large heat transefer coefficient because of large velocity.
Relationship between the heat transfer coefficient and the optimum amount of air and strong alkaline water is shown in Fig. 4. Paramete is length $L \mathrm{~mm}$ from output noozle to measuring point. When the distance (L) becomes smaller, heat transfer coefficient becomes larger. There are each peak at near $0.8 \mathrm{l} / \mathrm{min}$ of total flow rate of strong alkaline water. And when amount of air is $113.3 \mathrm{l} / \mathrm{min}$, total flow rate of strong alkaline water is $0.82 \mathrm{l} / \mathrm{min}$ and $\mathrm{L} \mathrm{mm}$ from output noozle to measuring pointis $50 \mathrm{~mm}$, heat transfer coefficent is about $10000 \mathrm{~W} / \mathrm{m}^{2} \mathrm{~K}$. These results clearly show that forced cooloing usingmist of strong alkaile water has influencevery large. Thus, it can be said that by using a machine tool in mist of strong alkaline water, thethermal deformation of machine structure can be effectively cooled.

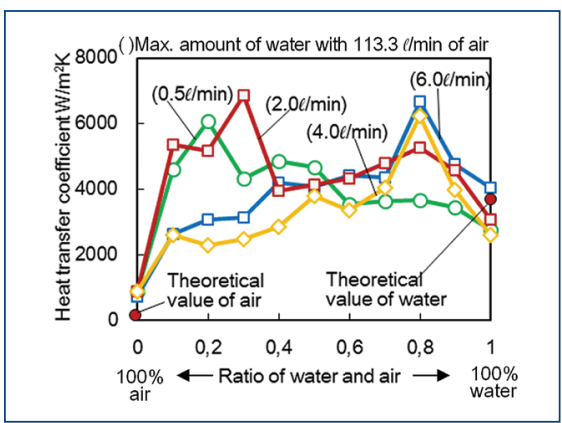

Figure 3. Relationship between the heat transfer coefficient and the mixture ratio of air and strong alkaline water

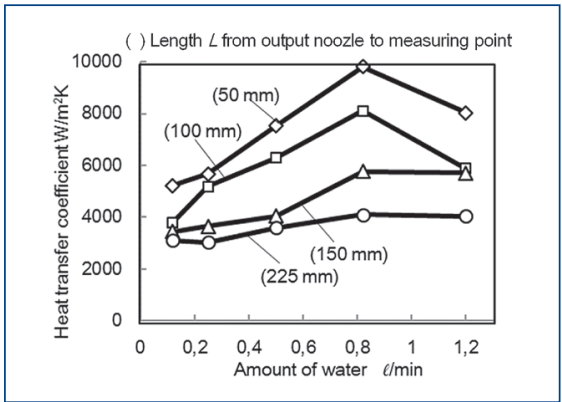

Figure 4. Relationship between the heat transfer coefficient and the optimum amount of air and strong alkaline water

\section{THERMAL DEFORMATION OF BENCH LATHE \\ IN MIST OF STRONG ALKALINE WATER}

Thermal deformation cause by heat from the friction of bearing unit can affect the machining accuracy of final cutting result. Here, the thermal deformation of bench lathe in the mist of strong alkaline water was measured. The same setup of bench lathe machine showed in Tab. 2 and Fig. 5 was used. There are 2 photographs before and after supplying mist of strong alkaline water in Fig. 5. The bench lathe is installed in vessel which sizes are L $1190 \times \mathrm{W}$ $980 \times \mathrm{H} 790 \mathrm{~mm}$. The detail setup for this experiment is shown in Fig. 6. Test bar was inserted into lathe chuck and the 4 dial gauges were used to measure the displacement of the test bar in horizontal and vertical direction during experiment. The experiment data was taken by compare between dry condition and using mist

\begin{tabular}{|c|c|c|}
\hline \multirow{3}{*}{ Head stock } & Height of center from bed & $177 \mathrm{~mm}$ \\
\hline & Height of center from floor & $337 \mathrm{~mm}$ \\
\hline & Spindle speed & Max. $3600 \mathrm{~min}^{-1}$ \\
\hline Bed & Size $(W \times L \times H)$ & $600 \times 360 \times 660$ \\
\hline Tool post & Stroke of $Y$ axis & $30 \mathrm{~mm}$ \\
\hline Table & Stroke of $Z$ axis & $200 \mathrm{~mm}$ \\
\hline Motor & Power & $0.75 \mathrm{~kW}$ \\
\hline \multicolumn{2}{|r|}{ Mass } & $200 \mathrm{~kg}$ \\
\hline
\end{tabular}

Table 2. Specification of the bench lathe in the experiment 


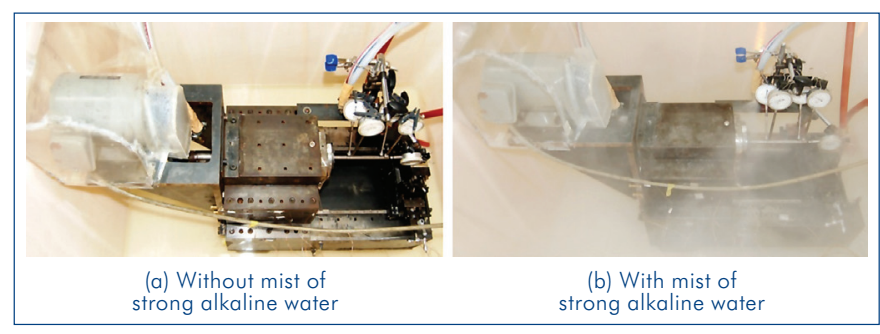

Figure 5. Photograph of the experimental setup

of strong alkaline water. The bench lathe was operated at spindle speeds $3600 \mathrm{~min}^{-1}$. Red circles are positions of thermo-couples for measuring temperatures on the machine structure. The developed nozzles were setted up on near centers $f$ front and rear surfaces of the head stock. The mixed air $(113.3 \mathrm{l} / \mathrm{min})$ and strong alkaline water $(0.82 \mathrm{l} / \mathrm{min})$ is supplied by each nozzle. Distance between the nozzle and the machine structure is $50 \mathrm{~mm}$.

Fig. 10 shows the experimental result of the temperature on the bench lathe at spindle tip surface (1), (6) and end of bed (12). At spindle speed $3600 \mathrm{~min}^{-1}$, the rise in temperature (the maximum values at

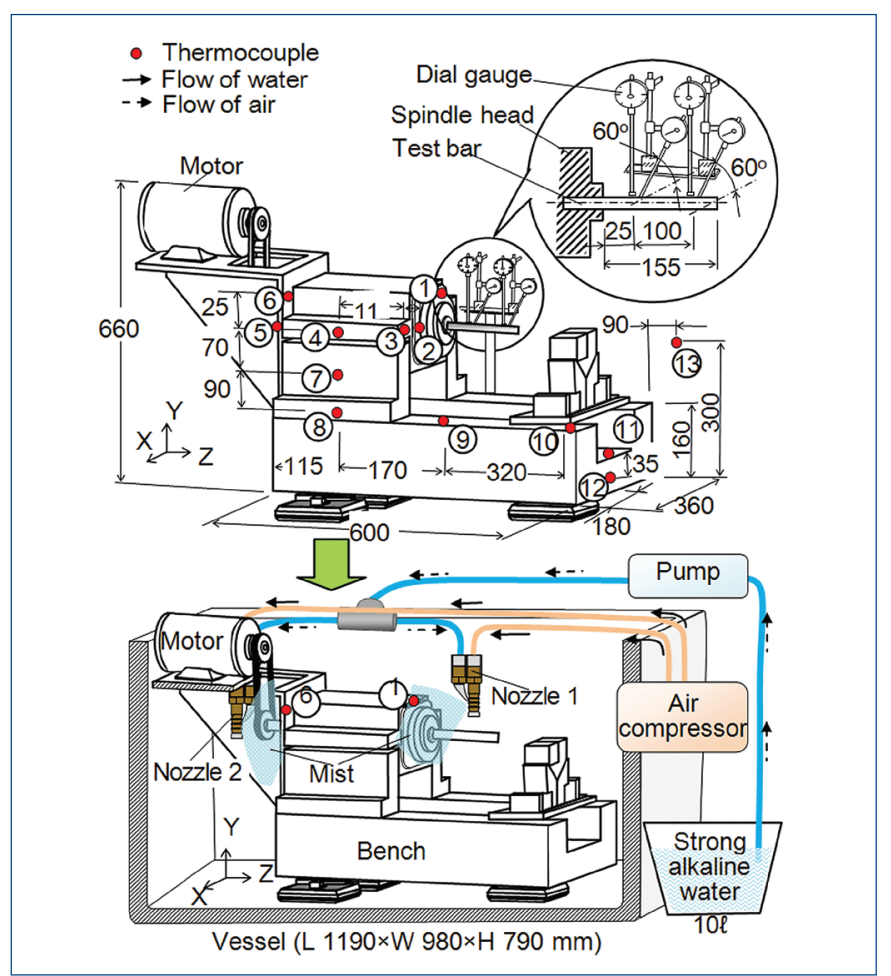

Figure 6. Schematic view of the experiment using the bench lathe in strong alkaline water mist

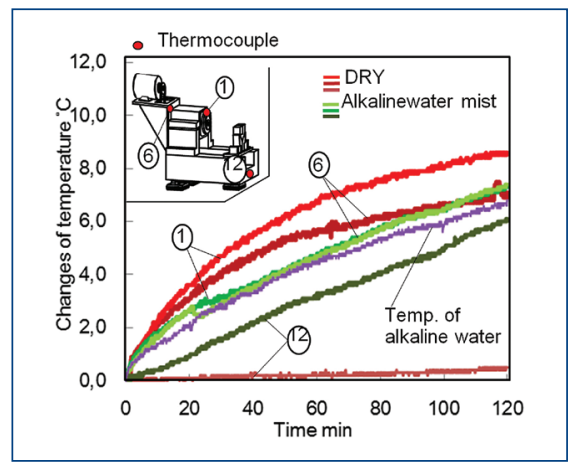

Figure 7. Temperature change of the bench lathe using strong alkaline water mist operated in $3600 \mathrm{~min}^{-1}$ steady state condition) at the spindle tip surface (1) which is the most influencing part of the machining accuracy were $8.3^{\circ} \mathrm{C}$ at dry cutting, $6.4^{\circ} \mathrm{C}$ for mist of strong alkaline. Temperature rising for mist of strong alkalineoccurred because the heat generated by microbubble device caused the pump become warm during continuously operation in two hours. At that time, if the forced cooling is used, temperature rising is restrained. However the forced cooling is never used in this research, because this research is performed for eath-friendly. In case of dry cutting, as temperature distribution on the machine structure is very large, thermal deformation will alsobecome very large. On the other hand, in case of mist of strong alkaline water, as temperature distribution is very small, thermal deformation will also become very small.

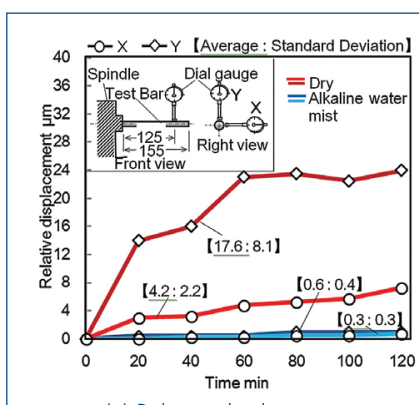

(a) Relative displacement

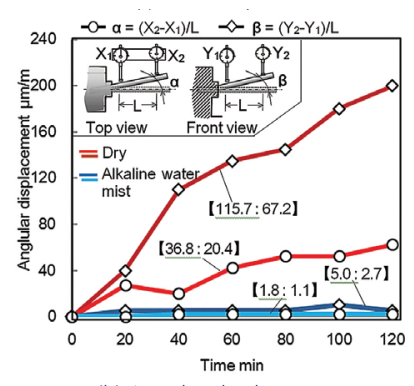

(b) Angular displacement
Figure 8 . Thermal deformation of the bench lathe in strong alkaline water mist at $3600 \mathrm{~min}^{-1}$

Fig. 12 show the relative displacement ( $X$ and $Y$ direction) and angular displacement ( $\alpha$ and $\beta$ direction) ofthe tip of test bar measured at operation speed $3600 \mathrm{~min}^{-1}$. The data between $20 \sim 120$ minwere divided into 6 intervals and the average values and standard deviation of each of the sixintervals are plotted. The results show that, in dry cutting, relative displacements arelarge with $\Delta \mathrm{X}=6.0 \mu \mathrm{m}, \Delta \mathrm{Y}=24.0$ $\mu$ mand angular displacements were $\alpha=55 \mu \mathrm{m} / \mathrm{m}$ and $\beta=200 \mu \mathrm{m} / \mathrm{m}$, in mist of strong alkaline water, the relative displacement are $\Delta \mathrm{X}=$ $0.6 \mu \mathrm{m}, \Delta \mathrm{Y}=0.9 \mu \mathrm{mand}$ angular displacements are $\alpha=3.6 \mu \mathrm{m} / \mathrm{m}$ and $\beta=9.0 \mu \mathrm{m} / \mathrm{m}$. When operated in mist of strong alkaline water, the thermal deformations in operation speeds reduced significantly. In case of mist of strong alkaline water, as the standerd deviations are very small, temerature changes are also very small, therefore thermal behavior is small and high stability. These results clearly show that relative displacement and angular displacement were restrained by usingmist of strong alkaile water and its influence was very large. Thus, it can be said that by using immersed bench lathe in mist of strong alkaline water, thethermal deformation of machine structure can be effectively suppressed and resulting high processing accuracy.

\section{CUTTING PROPERTY OF CNC MILLING MACHINE IN MIST OF STRONG ALKALINE WATER \\ 5.1 TOOL TEMPERATURE}

Cutting area on the CNC milling machine was filled by mist of strong alkaline water, and two tool temperatures were measured for evaluation of cooling property. Cutting conditions for tool temperature measurement are shown in Tab. 3. This is middle cutting. Experimental set-up is shown in Fig. 9. Amount of air is $113.3 \mathrm{l} / \mathrm{min}$, total flow rate of strong alkaline water is $0.82 \mathrm{l} / \mathrm{min}$ and $L \mathrm{~mm}$ from output noozle to measuring pointis $50 \mathrm{~mm}$. Work-piece was fixed to the spindle and tool was set to the vise on the table, because it is that the tool temperatures were measured without a hitch by thermocouples. Then temperature on the top of the tool was estimated by the measured temperatures and FEM analysis. Here theof model the toolare firstly made, and tool temperature with transient stateare calculated by FEM analysis. At that time, heat transfer coefficient and heat generation on the top of the tool for input data are changed 


\begin{tabular}{|c|c|c|}
\hline \multicolumn{3}{|c|}{ Cutting conditions } \\
\hline Cutting speed $80 \mathrm{~m} / \mathrm{min}$ & Feed speed $0.25 \mathrm{~mm} / \mathrm{rev}$ & Depth of cut $0.4 \mathrm{~mm}$ \\
\hline & Work piece \\
\hline & Material: $\mathrm{S} 50 \mathrm{C}$ \\
\hline & Tool (Bite) \\
\hline \multicolumn{3}{|c|}{ Coated carbide }
\end{tabular}

Tab.3. Cutting conditions for tool temperature measurement

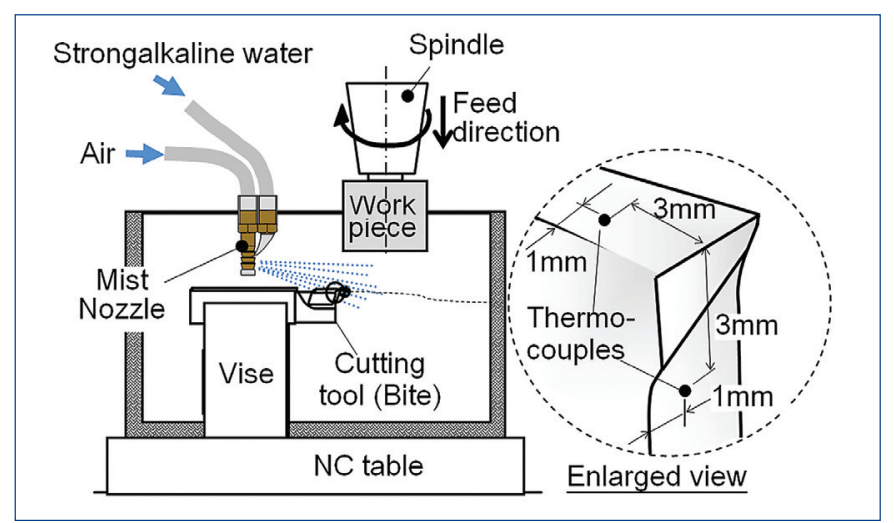

Figure 9. Experimental setup for measurement of tool temperature

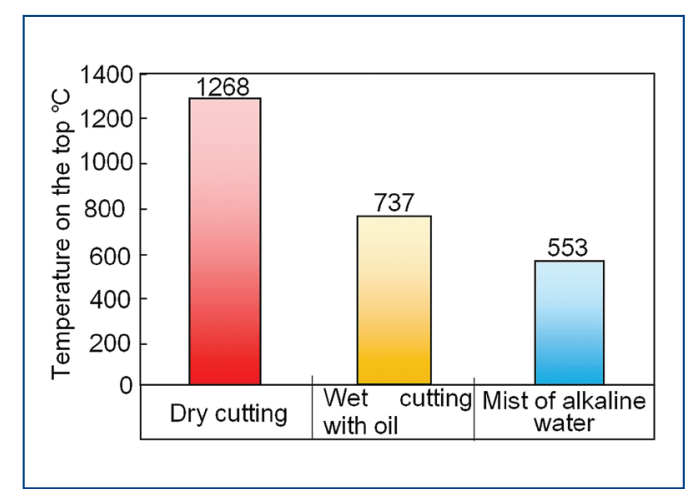

Figure 10. Experimental results for temperature on the top

one by one. When the result of the FEM analysis became same to the result of the two measured temperature, the calculated temperature on the top of the tool is adopted for its temperature.

Temperatures on the top of the tool were shown in Fig. 10. Dry cutting and wet cutting with oil were also shown for reference. Material of the used tool is coated carbide and its optimum temperature for cutting is about $800{ }^{\circ} \mathrm{C}$. Temperature on the top of the tool using mist of strong alkaline water was $44 \%$ of one of dry cutting and $75 \%$ of one of wet cutting with oil respectively. Mist of strong alkaline water is effective method for cooling tool.

\subsection{TOOL LIFE}

Tool life for evaluation of cutting using mist of strong alkaline water was performed. Cutting conditions for tool life test are shown in Tab. 4. This is middle cutting. Experimental set- up is shown in Fig. 11. Amount of air is $113.3 \mathrm{l} / \mathrm{min}$, total flow rate of strong alkaline water is $0.82 \mathrm{l} / \mathrm{min}$ and $L \mathrm{~mm}$ from output noozle to measuring pointis $50 \mathrm{~mm}$. Dry cutting and wet cutting with oil were also performed for reference. Endmill with 2 throw away tips was used for milling machining, becasue it is easy and certain for judgment of limit of tool life.

Results of the tool life test were shown in Fig. 12. Dry cutting and wet cutting with oil were also shown for reference. Tool life of the tool using mist of strong alkaline water was 2.5 times of one of dry

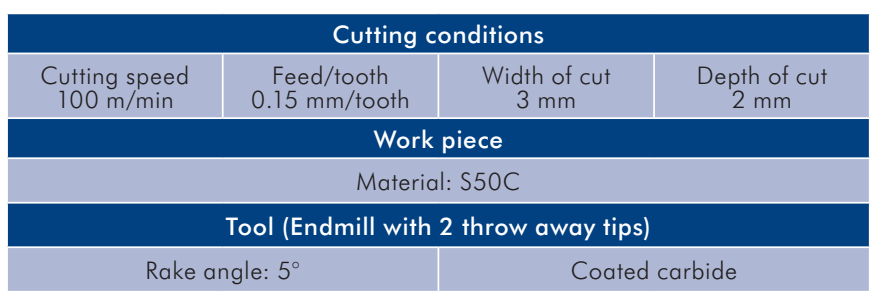

Tab.4. Cutting conditions for tool life measurement

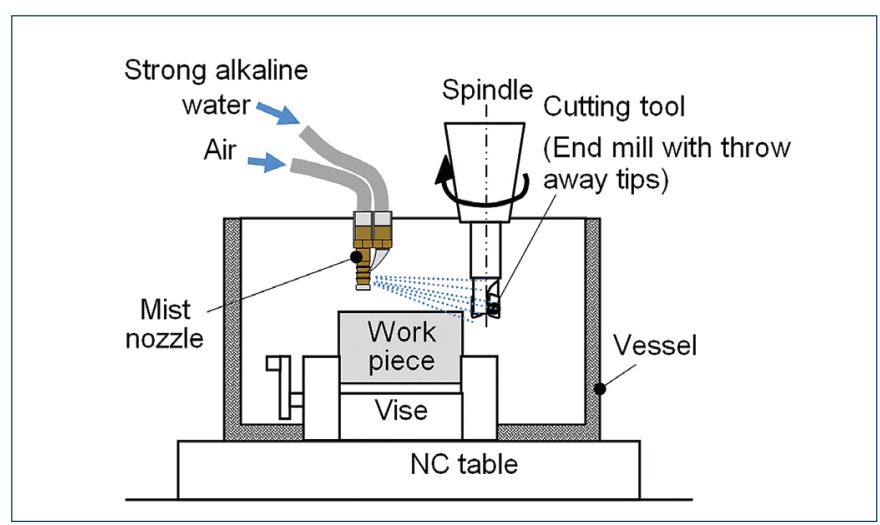

Figure 11. Experimental set-up for measurement of tool life and surface roughness

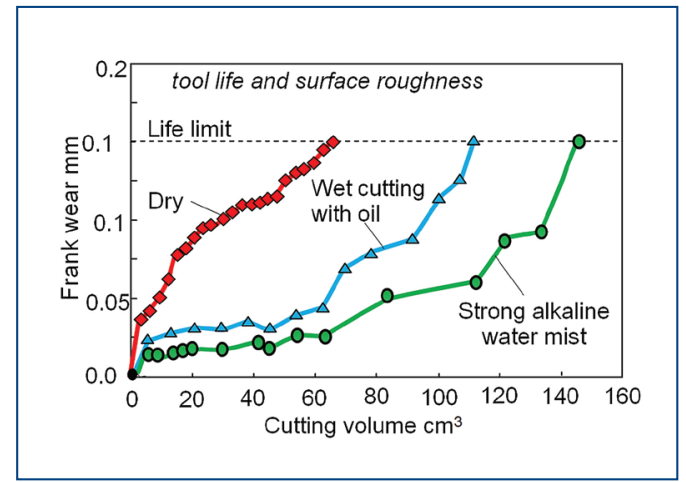

Figure 12. Results of tool life test

cutting and 1.4 times of one of wet cutting with oil respectively. Mist of strong alkaline water is effective method for extending tool life. In case of the cutting using mist of strong alkaline water, broken points crack were nothing in observation usig a microscope.

\subsection{SURFACE ROUGHNESS}

Surface roughness on the work-piece for evaluation of cutting using mist of strong alkaline water was measured. Cutting conditions for surface roughness test are same to the previous tool life test (see in Tab. 4). Experimental set-up is also same to the previous tool life test (see in Fig. 11). Amount of air is $113.3 \mathrm{l} / \mathrm{min}$, total flow rate of strong alkaline water is $0.82 \mathrm{l} / \mathrm{min}$ and $\mathrm{L} \mathrm{mm}$ from output noozle to measuring point is $50 \mathrm{~mm}$.

Results of the surface roughness test were shown in Fig. 13. Dry cutting and wet cutting with oil were also shown for reference. Surface roughness on the workpiece using mist of strong alkaline at limit of tool life water was $22 \%$ of one of dry cutting and $50 \%$ times of one of wet cutting with oil respectively. Surface roughness on the workpiece using mist of strong alkaline at start of the test is simular to that of dry cutting and wet cutting with oil. Mist of strong alkaline water is very effective method for improvement of surface roughness on the workpiece.

Thus, it can be said that by using practiceCNC milling machinewithmist of strong alkaline water, theheat generation for cutting can be effectively 


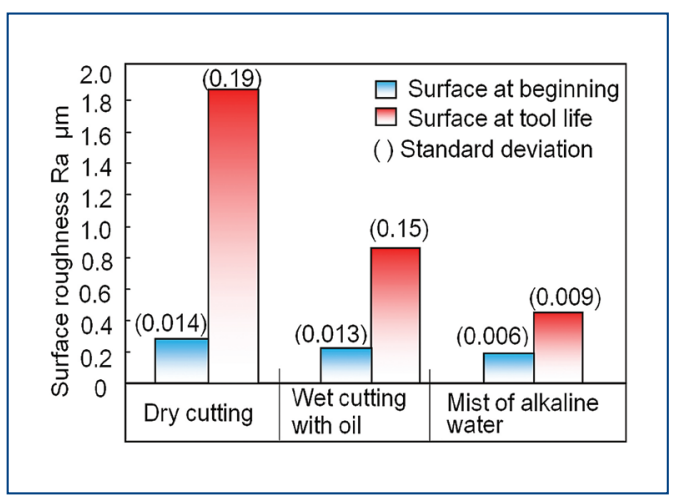

Figure 13. Results of surface roughness

removed and resultinglow tool temperature, long tool life and fine surafce roughness.

\section{CONSIDERATION REGARDING ENVIRONMENT FOR THIS SYSTEM}

Consideration regarding environment for this system was performed. When electrical energy was used for a manufacture, $\mathrm{CO}_{2}$ emission $\mathrm{CL}_{\mathrm{CO} 2}\left(\mathrm{~kg}-\mathrm{CO}_{2}\right.$ ) was calculated by equation (2) [e-Gov, 2013], [Ministry of the environment, 2013].

$$
C L_{\mathrm{CO} 2}=0.600 \times W_{\mathrm{E}}
$$

$W_{E}$ is the used electric power (W). And coefficient of relationship between the used electric power and the $\mathrm{CO}_{2}$ emission is $0.600 \mathrm{~kg}$ $\mathrm{CO}_{2} / \mathrm{kWh}$.

When oil was used for a manufacture, $\mathrm{CO}_{2}$ emission $\mathrm{CL}_{\mathrm{CO} 2}\left(\mathrm{~kg}-\mathrm{CO}_{2}\right)$ was calculated by equation (3) [Ministry of the environment, 2014].

$$
C L_{\mathrm{CO}_{2}}=D \times C \times Q \times 44 \div 12
$$

$D$ is quantity of discharge oil (kl), C is calorific value $(G J / k \ell), Q$ is quantity of carbon dioxide emissions (t-C/TJ). Here $40.2(\mathrm{GJ} / \mathrm{k \ell})$ is used for $C$ and $19.2(t-C / T J)$ is used for $Q$ [Greenhouse gas inventory office of Japan,2014].

In case of the conventional wet cutting with oil, $7 \mathrm{~kW}$ of electric power which are a CNC milling machine $(3.6 \mathrm{~kW})$, an oil pump $(1.2 \mathrm{~kW})$ and a refrigerator $(2.2 \mathrm{~kW})$ was used for cutting. Working hours of one day are 8 hours and working days of one year are 250 days. Cutting oil $680 \ell(=340 \ell \times 2$ times $)$ is changed for one year because of refresh. Cutting oil $360 \ell(=30 \ell \times 12$ months) is supplied for refill. $\mathrm{CO}_{2}$ emission $\mathrm{CL}_{\mathrm{CO} 2}\left(\mathrm{~kg}-\mathrm{CO}_{2}\right)$ for the used electrical energy and oil was calculated by equation (2) and (3) using these condition. Calculated results of $\mathrm{CO}_{2}$ emission $\mathrm{CL}_{\mathrm{CO} 2}\left(\mathrm{~kg}-\mathrm{CO}_{2}\right)$ for one year are shown in Tab. 5.

In case of the mist of strong alkaline water, $5.7132 \mathrm{~kW}$ of electric power which are a CNC milling machine $(3.6 \mathrm{~kW})$, a pump for removing chip $(0.0132 \mathrm{~kW})$, an air compressor $(0.95 \mathrm{~kW})$, a pump for mist $(0.4 \mathrm{~kW})$ and a generating unit for strong alkaline water $(0.75 \mathrm{~kW})$ was used for cutting. Working condition is similar to the conventional wet cutting with oil. However only generating unit for strong alkaline water was irregularity and independently worked such as Tab. 6. As oil isn't used in cooling using mist of strong alkaline water, the $\mathrm{CO}_{2}$ emission for only electrical energy is calculated. The $\mathrm{CO}_{2}$ emission $\mathrm{CL}_{\mathrm{CO} 2}\left(\mathrm{~kg}-\mathrm{CO}_{2}\right)$ for the used electrical energy was calculated by equation (2) using these condition. Calculated results of $\mathrm{CO}_{2}$ emission $\mathrm{CL}_{\mathrm{CO} 2}\left(\mathrm{~kg}-\mathrm{CO}_{2}\right)$ for one year are shown in Tab. 6.

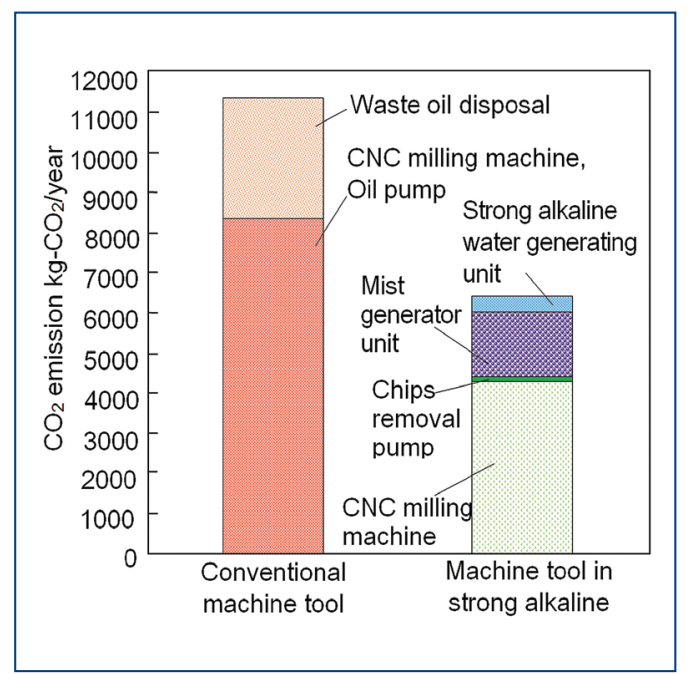

Figure 14. Comparison of $\mathrm{CO}_{2}$ emission

Comparison of environment protection between the conventional wet cutting with oil and the cutting using mist of strong alkaline water are shown in Fig. 14. Tool life of the tool using mist of strong alkaline water was $53 \%$ of one of wet cutting with oil. Because oil wasn't used in cutting using mist of strong alkline water.

Thus, it can be said that by using cutting withmist of strong alkaline water, the $\mathrm{CO}_{2}$ emission can be effectively reduced and resultingexcellent environment protection and earth-friendly.

\begin{tabular}{|c|c|c|c|}
\hline \multicolumn{2}{|c|}{ CNC milling machine, Oilpump\& Cooling unit } & \multicolumn{2}{|c|}{ Waste oil disposal } \\
\hline Power consumption $\mathrm{kW}$ & 7.0 & Cutting oil amount $\ell /$ year & 680 \\
\hline Use condition /year & $8 \mathrm{~h} \times 250$ days & Refill oil amount $\ell /$ year & 360 \\
\hline Consumption electric quantity $\mathrm{kWh}$ & 14000 & & \\
\hline $\mathrm{CO}_{2}$ emission $\mathrm{kg}-\mathrm{CO}_{2} /$ year & 8400 & $\mathrm{CO}_{2}$ emission $\quad \mathrm{kg}-\mathrm{CO}_{2} /$ year & 2943 \\
\hline Total $\mathrm{CO}_{2}$ emission $\mathrm{kg}-\mathrm{CO}_{2} /$ year & & 11343 & \\
\hline
\end{tabular}

Table 5. $\mathrm{CO}_{2}$ emission of conventional wet cutting with oil

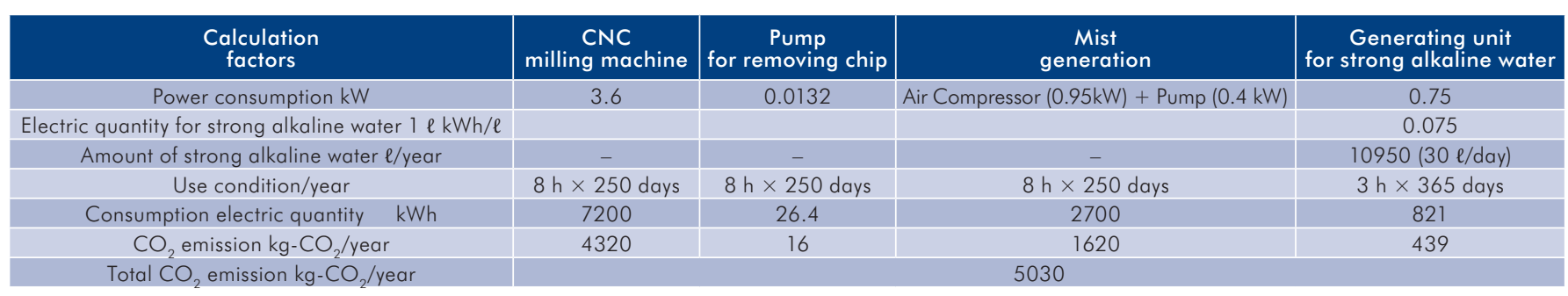

Table 6. $\mathrm{CO}_{2}$ emission of cutting in mist of strong alkaline water 


\section{CONCLUSION}

It is concluded from the results that;

(1) There are the corrosion resistance of several materials without aluminum, copper and their alloys in alkaline.

(2) deformations ( $=$ displacements $X$ and $Y$, angular displacementsa and $\beta$ ) of the bench lathe were effectively restrained by forced cooling using mist of strong alkaline water.

(3) When forced cooling usingmist of strong alkaline waterwas used in the cutting territory and compared with dry cutting, tool temperature during cutting with steel could reduce to $44 \%$, surface roughness on the work piece at limit of tool life could improve $22 \%$ and the tool life becam 2.5 times

(4) Forced cooling usingmist of strong alkaline water was very low cost and saving energy for eco-friendly.

\section{REFERENCES}

PAPER IN A JOURNAL

[Kaneko 2004] Kaneko, Y., Tanabe, I., Isobe M., and Maeda M. Development of a high precision lathe with countermeasure of environmental preservation for thermal deformation, Transactions of JapanSociety of Mechanical Engineers (Series C), Vol. 70, No. 700, (2004), pp. 3611-3616 (in Japanese).

[Simohira 1995] Simohira, S. Material science for crrosion and its protection, AGNE Gijutsu Center Inc. , (1995), pp. 30-32, 255-257, 287-288 (in Japanese).

[Tanabe 1999] Tanabe, I., Yamanaka, K., Mizutani, J. and Yamada, $Y$. A new design of lathe structure for reducing thermal deformation (Design of zero-center on three directions, self-compulsory cooling and design of thermal synchronism), Transactions of Japan Society of Mechanical Engineers (Series C), Vol. 65, No. 639, (1999), pp. 45084513 (in Japanese).

[Tanabe 2000] Tanabe, I. , Truong, H. M. and Yoshii, K. Turning with environment-friendly cooling method using water evaporation ( $7^{\text {st }}$ report, Cooling effect of water evaporation and its applicability to tool tip cooling), Transactions of Japan Society of Mechanical Engineers (Series C), Vol. 66, No. 643, (2000), pp. 1026-1030 (in Japanese). [Tanabe 2001] Tanabe, I. , Matsushita, K. and Truong, H. M. Study on self-forced cooling for reducing thermal deformation of machine tool (Modeling of self-forced cooling and its applicability), Transactions of Japan Society of Mechanical Engineers (Series C), Vol. 67, No. 660, (2001), pp. $2713-2718$ (in Japanese).

[Tanabe and Truong 2001] Tanabe, I. and Truong, H. M. Cutting with an environment-friendly cooling method using water evaporation
(Establishment of this cooling model and calculation of the suitable supply quantity of water), Transactions of Japan Society of Mechanical Engineers (Series C), Vol. 67, No. 664, (2001), pp. $4011-4016$ (in Japanese).

[Tanabe 2003] Tanabe, I. , Ikeda, S. and Urano, K. Estimation of optimum temperature for cooling oil on a spindle using inverse analysis of neural network (Effect of relearning), Transactions of Japan Society of Mechanical Engineers (Series C), Vol. 69, No. 679, (2003), pp. 819-824 (in Japanese).

[Tanabe 2011] Tanabe, I. , Ye, H. S. , lyama, T. and Abe, Y. Control of tool temperature using neural network for machining work-piece with low thermal conductivity, Transactions of Japan Society of Mechanical Engineers (Series C), Vol. 77, No. 776, (2011), pp. 1556-1564 (in Japanese).

\section{TECHNICAL REPORTS OR THESIS}

[e-Gov 2013] e-Gov, Ordinance related to calculation for carbondioxide equivalent greenhouse gas emissions with their business activities of specified emitters, Article 2 (2013), available from <http://law. e-gov. go. ip/htmldata/H18/H18F15002002003. html $>$ (accessed on 22 April, 2014) (in Japanese)

[Greenhouse gas inventory office of Japan 2014] Greenhouse gas inventory office of Japan, National GHGs Inventory Report of JAPAN (2014), available from <http://www-gio. nies. go. ip/aboutghg/ nir/2014/NIR-JPN-2014-v3. 0_J. pdf > (accessed on 22 April, 2014) (in Japanese)

[Ministry of the environment 2013] Ministry of the environment, Announcement of actual emission factor, adjusted emission per electric utility company in FY 2012 (2013), availablefrom <https://www. env. go. ip/press/press. php?serial=17512>(accessed on 22 April, 2014) (in Japanese).

[Ministry of the environment 2014] Ministry of the environment, Calculation method and emission factor on calculation, report and publication system (2014) available from <http://ghg-santeikohyo. env. go. ip/files/calc/itiran. pdf $>$ (accessed on 22 April, 2014) (in Japanese)

\section{CONTACTS}

Prof. Dr. Ikuo Tanabe

Nagaoka University of Technology,

Department of Mechanical Engineering

1603-1 Kamitomioka, Nagaoka, Niigata, 940-2188 Japan

tel.: ++0081-258-47-9727, e-mail tanabe@mech.nagaokaut.ac.jp http://ntic.nagaokaut.ac.jp/seeds-collection/75.htm 